in vivo $32: 1485-1489$ (2018)

doi:10.21873/invivo.11404

\title{
Inverse Relationship Between Polio Incidence in the US and Colorectal Cancer
}

\author{
STEVEN LEHRER ${ }^{1}$ and PETER H. RHEINSTEIN ${ }^{2}$ \\ ${ }^{1}$ Department of Radiation Oncology, Icahn School of Medicine at Mount Sinai, New York, U.S.A.; \\ ${ }^{2}$ Severn Health Solutions, Severna Park, MD, U.S.A.
}

\begin{abstract}
Background/Aim: Polio is predominantly an enteric viral infection that was progressively eradicated in the United States after the introduction of polio vaccine in the early 1950s. U.S. colorectal cancer rates have dropped steadily for individuals born between 1890 and 1950, but have been increasing for every generation born since 1950. Moreover, the lowest worldwide age adjusted rates of colorectal cancer in 2012 were in sub-Saharan Africa, Gambia and Mozambique, where polio has not been eradicated. In the current study, poliomyelitis incidence in US states before the introduction of polio vaccine was analyzed. Materials and Methods: Reported cases of poliomyelitis per 100,000 population by state 1932-1951 were from Centers for Disease Control. Colorectal cancer deaths per 100,000 in men (2005-2009) by US State are from the American Cancer Society. US state overweight and obesity data are from the Centers for Disease Control and Prevention $(C D C)$. Smoking data are from the CDC. Results: By US state, colorectal cancer incidence per 100,000 in men for 2005-2009 was inversely correlated with reported cases of poliomyelitis per 100,000 for 1932-1951 ( $r=-0.311$, $p=0.032)$. Colorectal cancer deaths per 100,000 in men in 2005-2009 were also inversely correlated with reported cases of poliomyelitis per 100,000 by state for 1932-1951 $(r=-0.493, p<0.001)$. The relationship between colorectal cancer deaths and polio incidence was significant $(\beta=-0.196, p=0.028)$ and independent of the effects of smoking $(\beta=0.289, p=0.012)$ and overweight $(\beta=0.547$, $p<0.001)$. The relationship in females with colorectal cancer was identical. Conclusion: Polio virus infection of cells of
\end{abstract}

This article is freely accessible online.

Correspondence to: Dr. Steven Lehrer, Box 1236 Radiation Oncology, Mount Sinai Medical Center, 1 Gustave L. Levy Place, New York 10029, U.S.A. E-mail: steven.lehrer@mssm.edu

Key Words: Polio virus, colorectal cancer, the Cancer Genome Atlas, $P V R$ gene. the colon may induce some degree of resistance to the development of colon cancer decades later. The effect of polio virus infection seems to be especially potent in reducing the rate of death from colon cancer.

Colorectal cancer rates have dropped steadily for individuals born between 1890 and 1950, but have been increasing for every generation born since 1950. Adults born in 1990 have twice the risk of colon cancer and four times the risk of rectal cancer compared to adults born in 1950 of comparable age. A total of 16,450 new cases of colon or rectal cancer will be diagnosed in 2018 in Americans under 50 years of age, according to the American Cancer Society. In 2014, $43 \%$ of colorectal cancer cases in those under 50 years old were in individuals aged 45 to 49 years, with a rise in colorectal cancer in adults as young as their 20s and 30s (1).

No one knows what may be driving the rise in cases. Lifestyle, environmental or genetic factors, obesity, cigarette smoking, a diet high in red or processed meats and lack of physical activity have been tied to increased risk (2). Other possible causes include prolonged use of antibiotics during adulthood, which raise the risk of developing precancerous polyps, possibly because antibiotics can alter gut bacteria (3).

Polio, predominantly an enteric viral infection, was progressively eradicated in the United States after the introduction of polio vaccine in the early 1950s. In the current study, we analyzed poliomyelitis incidence in US states before the introduction of polio vaccine. The Cancer Genome Atlas (TCGA) was used to examine the relationship of the polio virus cellular receptor $(P V R)$ to colon cancer incidence.

\section{Materials and Methods}

Reported cases of poliomyelitis per 100,000 population by state for 1932-1951 were from (4). Colorectal cancer deaths per 100,000 in men for 2005-2009 by US state were from (5). US state overweight and obesity data are from the Centers for Disease Control and Prevention (CDC; http://www.cdc.gov/obesity/data/adult.html). Smoking data are from the CDC (https://www.cdc.gov/ tobacco/data_statistics). Data from Alaska and Hawaii were not included because they were not U.S. states in 1951. 

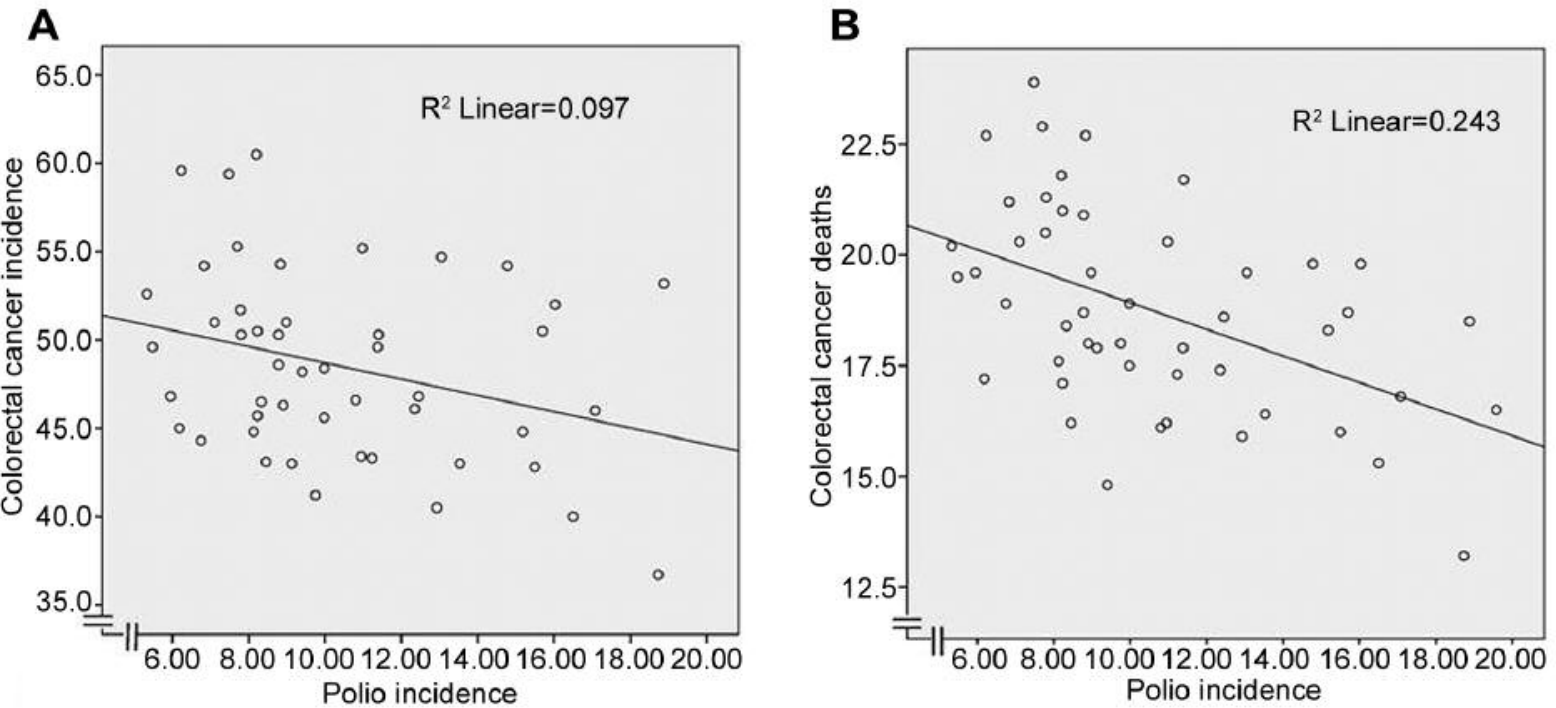

Figure 1. Colorectal cancer incidence (A) and deaths (B) per 100,000 in men in 2005-2009 versus reported cases of poliomyelitis per 100,000 population in 1932-1951 by US state ( $r=-0.311, p=0.032$ and $r=-0.493, p<0.001$, respectively). Polio data from 48 states are included. Hawaii and Alaska were not states in 1951.

Data from The Cancer Genome Atlas, Colon Cancer cohort (COAD) (551 samples) were analyzed. Tumor gene regulatory network visualization was from cBioportal (6). Tumor copy number segment analysis and microsatellite instability were from UCSC Xena browser (https://xenabrowser.net) (7).

Microsatellite instability (MSI) was evaluated by two measures. The older measure segregated data by presence or absence of MSI (8). The newer method segregated data into three groups: MSI-high, MSI-low, MS-stable (9). Data analysis was by multivariate linear regression, $t$-test, one-way analysis of variance and Tukey's posthoc test.

\section{Results}

Colorectal cancer incidence per 100,000 in men in 2005 2009 versus reported cases of poliomyelitis per 100,000 population in 1932-1951 is shown in Figure 1A. The correlation was significant $(\mathrm{r}=-0.311, p=0.032)$.

Colorectal cancer deaths per 100,000 in men in 2005-2009 versus reported cases of poliomyelitis per 100,000 population by state in 1932-1951 are shown in Figure 1B. The correlation was significant $(\mathrm{r}=-0.493, p<0.001)$. The relationship for females with colorectal cancer was identical.

Since obesity and cigarette smoking are risk factors for colorectal cancer, multivariate linear regression was performed with colorectal cancer deaths as the dependent variable, and polio incidence, overweight rates and smoking rates as independent variables. The relationship between colorectal cancer deaths and polio incidence was significant $(\beta=-0.196, p=0.028)$ and independent of the effects of smoking $(\beta=0.289, p=0.012)$ and overweight $(\beta=0.547$, $p<0.001)$.
Gene regulatory network with PVR is shown in Figure 2. This network was derived from TCGA colon cancer data (10). $P V R$ was not expressed, while SRC proto-oncogene, nonreceptor tyrosine kinase (SRC); adenopolyposis coli (APC); and Kirsten rat sarcoma virus $(K R A S)$ were expressed.

Because MSI lends distinctive features to colorectal cancer, the association of MSI with $P V R$ in the Cancer Genome Atlas TCGA Colon Cancer cohort (COAD) was examined (551 samples). MSI differed significantly in relation to $P V R$ copy number segments (Figure 3 ).

\section{Discussion}

Poliovirus enters the body through the mouth, infecting the first cells with which it comes in contact, those of the pharynx and intestinal mucosa. It enters by binding to an immunoglobulin-like receptor, the poliovirus receptor CD155 on the cell membrane (11). Poliovirus replicates within gastrointestinal cells for about 7 days, whence it spreads to the follicular dendritic cells in the tonsillar germinal centers, the intestinal lymphoid tissue ( $M$ cells of Peyer's patches) and the deep cervical and mesenteric lymph nodes, where it replicates prolifically. The virus then enters the bloodstream (12).

Cluster of differentiation 155 (CD155) is a protein that in humans is encoded by the $P V R$ gene (13). Activation of endothelial PVR with anti-PVR or interaction with its ligand DNAX accessory molecule-1 results in recruitment of the tyrosine-protein phosphatase non-receptor type 11 (SHP2) and this process is dependent on SRC kinases (14). SRC is highly similar to the $v$-src gene of Rous sarcoma virus. The 


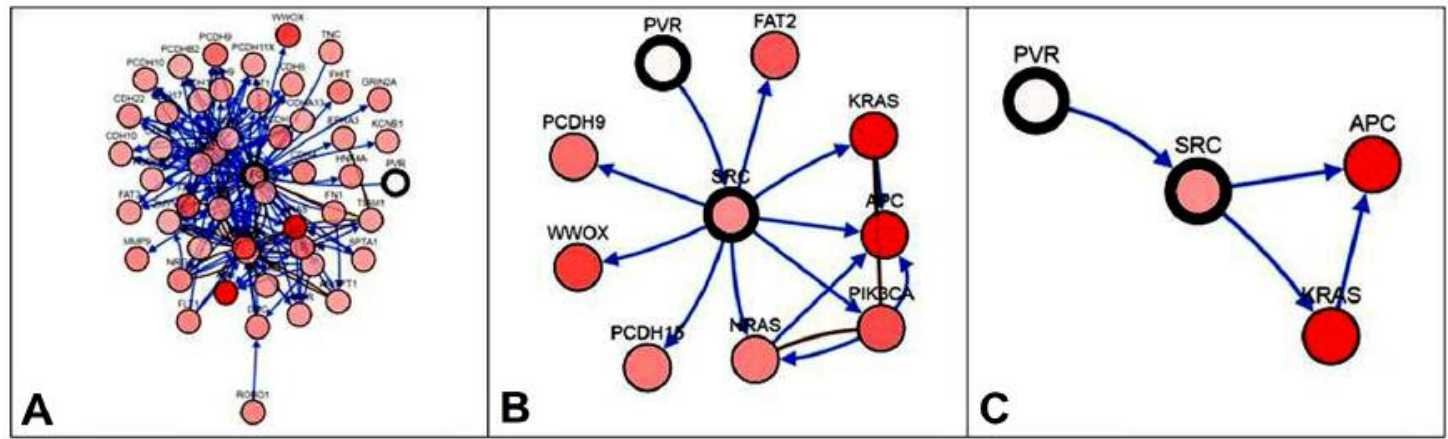

Figure 2. Gene regulatory network (The Cancer Genome Atlas colorectal cancer from cBioportal) with SRC proto-oncogene, non-receptor tyrosine kinase $(S R C)$ in the center (SRC is highly similar to the $v$-src gene of Rous sarcoma virus.), polio virus receptor (PVR) nearby, neighbors filtered by percentage alteration: A: No alteration, B: $10.3 \%$ alteration, C: $32.5 \%$ alteration. SRC, adenopolyposis coli (APC) and Kirsten rat sarcoma virus (KRAS) are all involved in colorectal cancer. Note that in C, APC and KRAS are strongly expressed (red), SRC less so (pink), and PVR not at all (white).
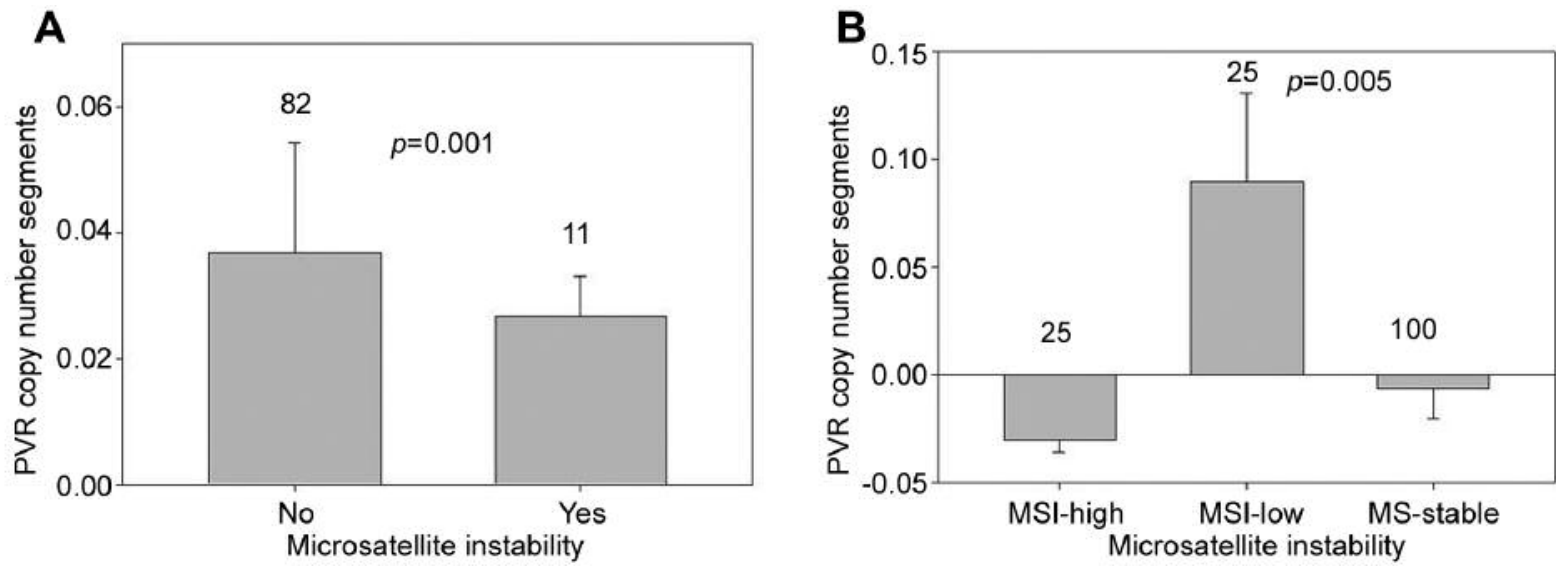

Figure 3. Polio virus receptor (PVR) copy number segments $\log 2$ (tumor/normal, mean + SEM) according to microsatellite instability (MSI) in colorectal cancer as a dichotomized variable (A) and as class (B). Note that in A, lack of MSI (82 tumors) was associated with significantly increased PVR copy number segments compared to microsatellite instability (11 tumors). In B, MSI-low (100 tumors) status was associated with significantly increased PVR copy number segments compared to MS-stable (25 tumors) and MSI-high (25 tumors) status ( $p=0.005$ ). Tukey's post hoc test showed that PVR copy number segments for those with MSI-high/MS-stable status were both significantly different from those with MSI-low status ( $p=0.01$ ). $P V R$ copy number segments for those with MSI-high and MS-stable colorectal cancer were not significantly different from one another ( $p=0.76$ ).

$P V R$ gene interacts within a network (Figure 2) containing $S R C$, Kirsten rat sarcoma virus $(K R A S)$ and adenopolyposis coli $(A P C)$, which are implicated in colorectal cancer (15).

As was noted, MSI varied significantly in relation to $P V R$ copy number segments. MSI is a result of loss of DNA mismatch-repair activity. MSI is found in $15 \%$ of colorectal cancer cases; 3\% have Lynch syndrome (hereditary nonpolyposis colorectal cancer) and the other $12 \%$ are sporadic. Colorectal tumors with MSI have specific features, including a propensity to arise in the proximal colon, lymphocytic infiltrate and a poorly differentiated, mucinous or signet ring appearance. They have a slightly better prognosis than colorectal tumors without MSI and respond to Programmed cell death protein 1 checkpoint inhibitors such as pembrolizumab and nivolumab (16). Therefore, $P V R$ expression might be a marker for tumor sensitivity to pembrolizumab or nivolumab.

Prior to the 20th century, polio infected mostly children 6 months to 4 years of age. Young children who contract polio generally suffer only mild symptoms but as a result they become permanently immune to the disease. In developed countries during the late 19th and early 20th centuries, improved sewage disposal, clean water supplies and better hygiene prevented infants and young children from encountering and developing 
immunity to polio. Exposure to poliovirus was therefore delayed until late childhood or adult life, when it was more likely to take the paralytic form (17). In $1 \%$ of infections, poliovirus spreads along nerve fiber pathways, preferentially replicating in and destroying motor neurons within the spinal cord, brain stem, or motor cortex. The destruction leads to the development of paralytic poliomyelitis, the various forms of which (spinal, bulbar and bulbospinal) differ only in the amount of neuronal damage and inflammation that occurs and the region of the CNS affected.

The data presented above suggest that polio virus infection of the cells of the colon may induce some degree of resistance to the development of colon cancer decades later. The incidence of colon cancer has begun to increase in adults who were vaccinated against polio as children, possibly because the cells of their colon were never infected by polio virus. The effect of polio virus infection seems to be especially potent in reducing the rate of death from colon cancer, perhaps mediated by CD155 and PVR.

Recombinant oncolytic poliovirus, PVSRIPO, has potent cytotoxic and innate inflammatory effects, mediating therapy in human breast and prostate cancer xenograft models (18); it may be a treatment for malignant glioma (19).

Oral attenuated live virus (Sabin) polio vaccine is no longer administered in the US because it can result in vaccine-associated paralytic poliomyelitis (in about three cases per million doses) (17). In the Democratic Republic of the Congo, a mutant of the type 2 virus in the oral vaccine has regained its virulence, spread and paralyzed 29 children (20). Public health officials fear that the virus may run rampant in Africa. Of interest is the fact that the lowest worldwide age-adjusted rates of colorectal cancer in 2012 were in sub-Saharan Africa, Gambia and Mozambique, where polio has not been eradicated (21).

It would be interesting to know if the live virus Sabin vaccine provided any protection against colorectal cancer. Was the vaccine-induced infection too limited, or does the Sabin vaccine lack something that is present in the wild-type polio virus? If the Sabin vaccine was protective, we should see a greater rate of colon cancer in patients vaccinated with the Salk killed virus vaccine. In order to determine whether Sabin oral polio vaccine might reduce the chance of colorectal cancer in persons at high risk, further investigation is warranted.

\section{References}

1 Wolf AMD, Fontham ETH, Church TR, Flowers CR, Guerra CE, LaMonte SJ, Etzioni R, McKenna MT, Oeffinger KC, Shih YT, Walter LC andrews KS, Brawley OW, Brooks D, Fedewa SA, Manassaram-Baptiste D, Siegel RL, Wender RC and Smith RA: Colorectal cancer screening for average-risk adults: 2018 guideline update from the American Cancer Society. CA Cancer J Clin 68: 250-281, 2018
2 Huxley RR, Ansary-Moghaddam A, Clifton P, Czernichow S, Parr CL and Woodward M: The impact of dietary and lifestyle risk factors on risk of colorectal cancer: a quantitative overview of the epidemiological evidence. Inte J Cancer 125: 171-180, 2009.

3 Cao Y, Wu K, Mehta R, Drew DA, Song M, Lochhead P, Nguyen LH, Izard J, Fuchs CS, Garrett WS, Huttenhower C, Ogino S, Giovannucci EL and Chan AT: Long-term use of antibiotics and risk of colorectal adenoma. Gut 67: 672-678, 2018.

4 Serfling Re and Sherman Il: Poliomyelitis distribution in the United States. Public Health Rep 68: 453-466, 1953.

5 American Cancer Society: Cancer Facts and Figures. CA Cancer J Clin 1-68, 2013. Avalaible from: https://www.cancer.org/ content/dam/cancer-org/research/cancer-facts-and-statistics/ annual-cancer-facts-and-figures/2013/cancer-facts-and-figures2013.pdf

6 Gao J, Aksoy BA, Dogrusoz U, Dresdner G, Gross B, Sumer SO, Sun Y, Jacobsen A, Sinha R, Larsson E, Cerami E, Sander $\mathrm{C}$ and Schultz N: Integrative analysis of complex cancer genomics and clinical profiles using the cBioPortal. Sci Signal 6: 11,2013

7 Goldman M, Craft B, Brooks AN, Zhu J and Haussler D: The UCSC Xena Platform for cancer genomics data visualization and interpretation. bioRxiv 326470, 2018. https://doi.org/10.1101/ 326470

8 Thibodeau SN, Bren G and Schaid D: Microsatellite instability in cancer of the proximal colon. Science 260: 816, 1993.

9 Ogino S, Nosho K, Kirkner GJ, Kawasaki T, Meyerhardt JA, Loda M, Giovannucci EL and Fuchs CS: CpG island methylator phenotype, microsatellite instability, BRAF mutation and clinical outcome in colon cancer. Gut 58: 90-96, 2009.

10 Nacu S, Critchley-Thorne R, Lee P and Holmes S: Gene expression network analysis and applications to immunology. Bioinformatics 23: 850-858, 2007.

11 He Y, Mueller S, Chipman PR, Bator CM, Peng X, Bowman VD, Mukhopadhyay S, Wimmer E, Kuhn RJ and Rossmann MG: Complexes of poliovirus serotypes with their common cellular receptor, CD155. J Virol 77: 4827-4835, 2003.

12 Tuthill TJ, Bubeck D, Rowlands DJ and Hogle JM: Characterization of early steps in the poliovirus infection process: receptor-decorated liposomes induce conversion of the virus to membrane-anchored entry-intermediate particles. J Virol 80: 172-180, 2006.

13 Koike S, Horie H, Ise I, Okitsu A, Yoshida M, Iizuka N, Takeuchi K, Takegami T and Nomoto A: The poliovirus receptor protein is produced both as membrane-bound and secreted forms. EMBO J 9: 3217-3224, 1990.

14 Sullivan DP, Seidman MA and Muller WA: Poliovirus receptor (CD155) regulates a step in transendothelial migration between PECAM and CD99. Am J Pathol 182: 1031-1042, 2013.

15 Wong HL, Wah Ng LP, Koh SP, Chi Chan LW, Kwan Wong EY, Xue VW andy Tsang HF, Ching Chan AK, Chiu KY, Cheuk W and Cesar Wong SC: Hotspot KRAS exon 2 mutations in CD166 positive colorectal cancer and colorectal adenoma cells. Oncotarget 9: 20426-20438, 2018.

16 Boland CR and Goel A: Microsatellite instability in colorectal cancer. Gastroenterology 138: 2073-2087, 2010.

17 Oshinsky DM: Polio: an American story. Oxford University Press, 2005. 
18 Holl EK, Brown MC, Boczkowski D, McNamara MA, George DJ, Bigner DD, Gromeier $M$ and Nair SK: Recombinant oncolytic poliovirus, PVSRIPO, has potent cytotoxic and innate inflammatory effects, mediating therapy in human breast and prostate cancer xenograft models. Oncotarget 7: 79828-79841, 2016.

19 Desjardins A, Gromeier M, Herndon JE, Beaubier N, Bolognesi DP, Friedman AH, Friedman HS, McSherry F, Muscat AM, Nair S, Peters KB, Randazzo D, Sampson JH, Vlahovic G, Harrison WT, McLendon RE, Ashley D and Bigner DD: Recurrent Glioblastoma Treated with Recombinant Poliovirus. New England Journal of Medicine 379: 150-161, 2018.
20 Roberts L: Polio outbreaks in the DRC threaten eradication effort. Science 361: 10, 2018.

21 Arnold M, Sierra MS, Laversanne M, Soerjomataram I, Jemal A and Bray F: Global patterns and trends in colorectal cancer incidence and mortality. Gut 66: 683-691, 2017.

Received August 25, 2018

Revised September 20, 2018

Accepted September 28, 2018 